\title{
Reviews
}

\section{Changing Patterms in Mental Health Care: Report on a WHO Worling Group EURO Reports and Studies No 25. HMSO. Pp 50. Sw. fr. 4}

This interesting and well-written booklet summarises the proceedings of a WHO working group composed chiefly of psychiatrists from thirteen European countries who met in Cologne for a few days towards the end of 1978 to talk about patterns of mental health care. In the introduction, the now extensive common ground concerning trends in underlying problems (greater emphasis on dementia, alcoholism, drug addition, parasuicide, difficulties of childhood and adolescence) and their efiects on service use and need, together with the difficulties encountered in the search for a humane 'community care', are reviewed with admirable economy.

A substantial section is devoted to a description of experimental services in Trieste, Mannheim, Stockholm and Leningrad. There has been a good deal of curiosity in this country about the implementation of the new Italian law. Rumours of an anti-psychiatry revolution have circulated. The story as told here (based on an account by Dr D. H. Bennett) suggests a crash programme in which developments that have taken us thirty years have been concentrated into ten. The same mistakes have been made and the same lessons learned, but much more dramatically. One major question for the future-how to care adequately for people who persist in being disabled in spite of all theories to the contrary - has an ironically familiar ring. One would just like to have read a word or two about the problems of the relatives who, in Trieste as elsewhere, carry much of the responsibility for the innovations professional people introduce.

Descriptions of the three other services are based on accounts by the professionals involved. In the first two cases, it is mainly a question of trying to implement ideas that are well accepted elsewhere, though the Stockholm experience poses interesting questions about the extent to which a psychiatric service should be made available 'on demand' to the general public.

The Leningrad story is not so much of an innovation as of continued development. The service sounds as though it provides well for chronically disabled people. There is also much emphasis on primary prevention. But, as the rapporteur (Professor Brian Cooper) remarks, we have not yet progressed to a stage at which we can talk about comparative evaluation.

Briefer accounts are given of schemes of care for certain special groups non-hospital accommodation for the chronically mentally disabled in Baden-Württemberg, a boardingout scheme at Kortenberg in Belgium, a drop-in advisory centre for young people in Zurich, and crisis intervention services in several countries (based on a survey by Professor J. E. Cooper). The value of self-help groups, such as our own National Schizophrenia Fellowship, is emphasized.

British psychiatrists who read the booklet will find familiar problems being considered in unfamiliar contexts; a useful opportunity to broaden one's point of view.

\section{Institute of Psychiatry}

J. K. Wing

\section{London SE5 8AF}

Representing the Mentally II and Handieapped, a Guide to Mental Health Review Tribunals by Larry Gostin and Elaine Rassaby. Published by Quartermaine House for MIND. 1980. 215 pp. £3.50.

'Your representative owes you, not his industry only, but his judgement; and he betrays instead of serving you if he sacrifices it to your opinion'. So said Edmund Burke to the electors of Bristol in 1774, and fortunately our MPs agree, otherwise for a start we would surely have capital punishment back. Mr Gostin and Ms Rassaby of MIND would, however, strongly disagree. They believe a patient's representative should not interpret his role as one of making judgements considered to be in the patient's best interests: 'to do so is to adopt a highly paternalistic and inappropriate role'. Instead they insist the representative should adopt a 'strict instructions' approach and they castigate any representative who sees as his objective a Mental Health Review Tribunal (MHRT) decision which best promotes the health and safety of the patient. The MIND belief is that the representative has 'won' if the Tribunal decides in favour of the patient's discharge.

On the one hand, then, the authors contend that the patient is competent to decide what is in his best interests, but on the other they would not put this forward as a reason why the majority of detained patients do not ask for a legal representative at a Tribunal, or as a reason for not asking for a Tribunal hearing. Perhaps not a few of those who do not exercise their right to have Tribunals recognize that it is in their interests to remain in hospital. This book is based on assumptions such as that there is an 'unmet need' for legal representation at MHRTs of 20,000 patients a year. The authors fail to point out (it does not suit their case) that 90 per cent of these patients are on short-term detention orders and most remain as informal patients on the expiry of the order. However, this is said to be 'a national scandal', the reason so many do not ask for legal representation is because of their 'vulnerability, the effects of institutionalization, mental disorder and the frequent use of tranquillizers'. While elements of truth in some of these assertions must be recognized, equally no evidence can be produced to sub- 